\title{
A Tripartite Evolutionary Game Analysis of the Co-Construction of an International Transport Corridor
}

\author{
Yang Lei $\mathbb{I D}^{1,2}$ \\ ${ }^{1}$ School of Economics and Management, Chongqing Jiaotong University, Chongqing, China \\ ${ }^{2}$ European Studies Center, Chongqing Jiaotong University, Chongqing, China \\ Correspondence should be addressed to Yang Lei; leiyang@cqjtu.edu.cn
}

Received 19 April 2021; Revised 18 May 2021; Accepted 24 May 2021; Published 2 June 2021

Academic Editor: Abdul Qadeer Khan

Copyright ( 2021 Yang Lei. This is an open access article distributed under the Creative Commons Attribution License, which permits unrestricted use, distribution, and reproduction in any medium, provided the original work is properly cited.

\begin{abstract}
The construction and development of international transport corridors have become a means of cross-border space governance and promote the flexibility of international industrial chains and supply chains. Due to the uncertainty of cooperation, the development of international transport corridors entails a long-term and complex system of engineering. This paper evaluates a tripartite evolutionary game model on the cooperative construction of international transport corridors (including origin, transit, and destination countries) and analyzes the cooperation mechanism and influencing factors. The cooperative construction of international transport corridors is complex. Factors such as willingness to cooperate, transfer payments, sunk costs, and reputation have a positive impact on the cooperative construction of international transport corridors, but excessive transfer payments hinder cooperation. To promote the construction of international transport corridors, all parties need to have a strong willingness to cooperate; otherwise, the cooperation agreement has a greater probability of becoming invalid. International transport corridors with good development prospects and benefits would accelerate construction progress with the active efforts of participating countries.
\end{abstract}

\section{Introduction}

An international transport corridor connects logistics hubs that are located in different countries through one or more modes of transport and enables the interconnection of economies located in different geographical spaces $[1,2]$. Transport agreements and rules enable international transport corridors to transfer international trade goods to destinations at a reasonable cost and time, promote economic and trade exchanges between different regions, promote economic and social development along the routes, and enhance the welfare of residents [3-5]. International transport corridors are developed based on two main goals: (1) to increase the efficiency of the corridor's transportation and logistics processes in order to improve connectivity and transportation networks and (2) to promote economic development in areas along the corridor [6-8]. Thus, the transport corridor development strategy is a widely adopted practice to narrow regional development gaps $[9,10]$.
The construction and operation of an international transport corridor is a complex systematic project with many influencing factors and numerous relationships that require coordination. Modern international corridors that perform well are not constructed overnight, but instead are usually developed in a coordinated manner spanning many years [11]. The construction and operation of an international corridor involves many stakeholders, such as government investment decision makers, transport management authorities, carriers, shippers, and customs and tax departments. The willingness of each stakeholder to improve the performance of the corridor depends largely on the potential benefits gained [12]. Therefore, the construction of an international transport corridor must consider interests and needs of diverse stakeholders [13].

In 1992, the European Union launched the "Borderless Europe" program, which aims to develop cross-border transportation corridors through the construction of crossborder transportation infrastructure, promote the 
interconnection of countries within the EU, and promote the formation of a unified EU market [14]. Since then, research on "international corridors" or "cross-border corridors" has become rich, and corridor development strategies have become increasingly popular. In the past three decades, various development strategies based on transport corridors have emerged in an endless stream. There are dozens of cross-border transport corridors at the international level, such as the development of the Greater Mekong Subregion [15], the Europe-Caucasus-Asia Transport Corridor [16], the New Eurasian Continental Bridge Economic Corridor, the Turkey Middle Corridor [17], Africa North-South Economic Development Corridor, and the Asia-Africa Development Corridor.

Numerous cases of international transport corridor development have shown that the willingness and cooperation of the countries in the corridor have an important impact on the spatiotemporal evolution and efficiency improvements of the corridors. In 1991, the Chinese Railway and the Kazakhstan Railway were connected, and the second Eurasian Land Bridge was officially opened [18]. In 2011, Chongqing took the lead in using this line to develop the China-Europe Express. With the cooperation of countries along the route, the second Eurasian Land Bridge has become increasingly convenient. Since then, the volume of China-Europe freight trains has grown rapidly [19], the transportation efficiency of the corridor has improved continuously, and the economic and trade promotion effect of the corridor has been continuously released, which has played an important role in supporting cross-border trade between China and Europe. As early as 2000, Russia, Iran, and India jointly proposed the International North-South Transport Corridor (INSTC). In recent years, India has pushed for this corridor to compete with the Belt and Road Initiative [20]. However, due to prevailing unwillingness to cooperate and differences in investment methods, progress in the North-South Transport Corridor has been slow, and the corridor is still operating at low efficiency.

Co-construction of international transport corridors requires the participation and cooperation of countries along the route. Whether countries are willing to invest in the corridor to improve its connectivity mainly depends on the tradeoff between various "payments" and "benefits." In addition, it is often difficult for countries along international transport corridors to make decisions with absolute certainty when deciding whether to participate and, if so, how to participate in corridor construction. Various political forces over the years have differed in their idiosyncrasies, often contradicting each other, and have hesitated to varying degrees on whether to participate in cooperation. Therefore, the level of cooperation in the construction of international transport corridors remains uncertain. Improving the efficiency of an international transport corridor is a long-term, complex, and systematic project, often involving repetition in construction, unforeseen problems, hesitation to remain involved, negotiation, dishonesty, or progress disruption among countries along the route. If countries along the route actively participate in the construction, the evolution of international transport corridors accelerates, and the efficiency of international transport corridors improves more quickly. Otherwise, corridors' development would slow or even stall.

The modes of interaction between countries are affected by a variety of complex factors. The success or failure of transnational projects depends on whether countries can reach a consensus on the sharing of benefits and costs [21]. In order to deeply understand and interpret the cooperative construction mechanism of international transport corridors, it is necessary to use complexity science and information systems for analysis. Evolutionary game theory is a classic application of complex science in the fields of social science and economics. It can model some complex real-life events [22]. Evolutionary game theory does not require the game subject to conform to complete rationality nor does it require that information be fully known in advance; it also offers the advantage of enabling dynamic analysis [23]. Evolutionary game theory is suitable for analyzing multiparty decision-making and can incorporate a variety of scenarios and influencing factors into the analysis model [24-26]. Some scholars have used evolutionary game theory to construct a game model of two decision-making subjects to analyze the construction of international transport corridors [27], while others have incorporated project partners and the public of the host country into the analysis to construct a tripartite evolutionary game model [28]. This paper uses evolutionary game theory to construct a dynamic evolutionary game model to investigate the mechanism for the cooperation and co-construction of international transport corridors.

\section{Evolutionary Game Model}

\subsection{Model Assumptions and Parameter Settings}

2.1.1. Participants. Participating countries and stakeholders of various types of international corridors have unique differences. To generalize the analysis, the researcher assumes that participating countries of a certain planned international corridor are three bounded and rational game parties, divided into the origin country $\left(N_{1}\right)$, the destination country $\left(N_{2}\right)$, and the transit country $\left(N_{3}\right)$. The spatial relationship between them is shown in Figure 1. The participating countries of the international corridor are assumed heterogeneous. The origin and destination country are global or regional powers with relatively high levels of development. There is thus strong motivation for the interconnection between them, for example, to reduce international trade logistics costs, to improve the accessibility of border areas, and to increase international influence. Compared with the origin country and destination country, the transit country has a relatively low level of development and relatively weak strength.

2.1.2. Cooperation Strategy. In the game of the cooperative construction of international transport corridors, the origin country and destination country are the main forces involved. Both choose whether to participate in the construction of international corridors based on factors such as 


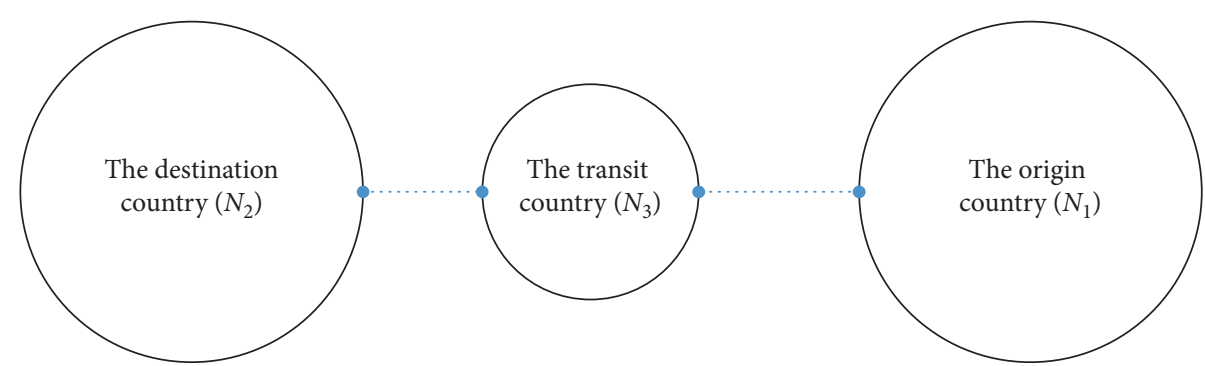

FIGURE 1: The tripartite main body in the construction of an international transport corridor.

comprehensive environment and cost versus benefits. Therefore, its strategy set is (participate, not participate). The transit country is a secondary force in the construction of international transport corridors, but its attitude and participation in construction are crucial to the successful development of the entire corridor. Due to the constraints of a comprehensive national strength and development foundation, the transit country generally does not adopt direct rejections for interconnection initiatives initiated by neighboring powers. On the contrary, there is a possibility and motivation to engage in free riding. Therefore, it is assumed that the transit country has two strategies to choose from strong or weak participation. Under the state of strong participation, the transit country actively responds to the initiatives of other countries during the construction of the corridor, actively participates in the planning and construction of the corridor, provides a good construction environment, invests corresponding resources, and actively promotes the formation of interconnection. Under the state of weak participation, transit countries behave as opportunistic or passive participant. This is mainly manifested in the active signing of relevant written agreements, while only basic effort and cost are expended toward corridor construction and regional interconnection, and the transit country often trusts that other countries will invest more. Therefore, the strategy set of transit countries is set as (strong participation, weak participation).

2.1.3. Benefits from Cooperation. The overall completion and operation of the planned international corridor can significantly reduce transportation costs along the route, improve regional accessibility, and promote international trade. In the model, $r_{i}(i=1,2,3)$ represents benefits and $N_{i}(i=1,2,3)$ gains from the construction and operation of the international corridor. When either $N_{1}$ or $N_{2}$ chooses "not to participate" and $N_{3}$ chooses "strong participation," the overall "multilateralism" degenerates into local "bilateralism." Although the entire corridor is difficult to build successfully, it can be initially built into a "cross-border corridor." In reality, this situation often occurs. Set $\theta_{i} r_{i}$ represents the benefits that $N_{i}$ gains from the partial completion and operation of the corridor, and $0<\theta_{i}<1$ $(i=1,2,3)$.

2.1.4. Costs for Cooperation. Variables $c_{1}$ and $c_{2}$ represent the benchmark cost for $N_{1}$ and $N_{2}$ when they choose to participate in the development of the corridor, including planning, coordination, construction, and management costs. When a country participates in the construction of an international transport corridor, its benefits are greater than the benchmark cost of its participation, so we set $r_{1}>c_{1}$ and $r_{2}>c_{2}$. Variables $\alpha$ and $\beta$ indicate the incentive for international transfer payments and assistance provided by $N_{1}$ and $N_{2}$ to $N_{3}$ when $N_{3}$ chooses the strong participation scenario. Variables $e_{1}$ and $e_{2}$ indicate the additional cost of $N_{1}$ and $N_{2}$ choosing to participate in corridor construction when $N_{3}$ chooses weak participation. Variable $c_{3}$ indicates the benchmark cost of $N_{3}$ choosing weak participation, and $e_{3}$ indicates the additional cost of $N_{3}$ choosing strong participation.

2.1.5. Punishment Setting. Since $N_{1}$ and $N_{2}$ are global or regional powers, any unilateral and voluntary abandoning of corridor construction will incur sunk costs and loss of international reputation. Variables $w_{1}$ and $w_{2}$ denote the sunk costs and loss of international reputation for $N_{1}$ and $N_{2}$ when they unilaterally and voluntarily abandon the construction of the international corridor.

2.1.6. Probability Setting. In the evolutionary game model of international corridor cooperation and co-construction, $N_{1}$, $N_{2}$, and $N_{3}$ make strategic choices based on their respective positions and willingness. Assume that $N_{1}$ chooses "participation" at a rate of $x$ and chooses "not participating" at a rate of $1-x$; assume that $N_{2}$ chooses "participation" at a rate of $y$ with a "not participation" ratio of $1-y$; assume that $N_{3}$ chooses "strong participation" at a rate of $z$ and chooses "weak participation" at a rate of $1-z$, in which $x, y, z \in[0,1]$.

2.2. Payment Matrix. Based on the above basic assumptions and parameter settings, the payment matrix of the tripartite game model of international corridor cooperation and coconstruction can be obtained, as shown in Tables 1 and 2 .

\subsection{Analysis of Evolutionary Stable Strategies}

2.3.1. Expectation Revenue Function. Variable $U_{N_{1}}^{1}$ represents the revenue of $N_{1}$ when choosing the "participating" strategy, while $U_{N_{1}}^{2}$ represents the revenue of $N_{1}$ when choosing the "not participating" strategy, and $\bar{U}_{N_{1}}$ 
represents the expected revenue. According to Tables 1 and 2, $U_{N_{1}}^{1}, U_{N_{1}}^{2}$, and $\bar{U}_{N_{1}}$ are as follows:

$$
\begin{aligned}
U_{N_{1}}^{1} & =z\left[y\left(r_{1}-c_{1}-\alpha\right)+(1-y)\left(\theta_{1} r_{1}-c_{1}-\alpha\right)\right]+(1-z)\left[y\left(r_{1}-c_{1}-e_{1}\right)+(1-y)\left(-c_{1}\right)\right] \\
& =y\left(r_{1}-e_{1}\right)+z\left(\theta_{1} r_{1}-\alpha\right)+y z\left(e_{1}-\theta_{1} r_{1}\right)-c_{1}, \\
U_{N_{1}}^{2} & =z y\left(-w_{1}\right)+(1-z) y\left(-w_{1}\right)=-y w_{1}, \\
\bar{U}_{N_{1}} & =x U_{N_{1}}^{1}+(1-x) U_{N_{1}}^{2} .
\end{aligned}
$$

Variable $U_{N_{2}}^{1}$ represents the revenue of $N_{2}$ when choosing the "participating" strategy, while $U_{N_{2}}^{2}$ represents the revenue of $\mathrm{N}_{2}$ when choosing the "not participating" strategy, and $\bar{U}_{N_{2}}$ represents the expected revenue. According to Tables 1 and 2, $U_{N_{2}}^{1}, U_{N_{2}}^{2}$, and $\bar{U}_{N_{2}}$ are as follows:

$$
\begin{aligned}
U_{N_{2}}^{1} & =z\left[x\left(r_{2}-c_{2}-\beta\right)+(1-x)\left(\theta_{2} r_{2}-c_{2}-\beta\right)\right]+(1-z)\left[x\left(r_{2}-c_{2}-e_{2}\right)+(1-x)\left(-c_{2}\right)\right] \\
& =x\left(r_{2}-e_{2}\right)+z\left(\theta_{2} r_{2}-\beta\right)+x z\left(e_{2}-\theta_{2} r_{2}\right)-c_{2}, \\
U_{N_{1}}^{2} & =z x\left(-w_{2}\right)+(1-z) x\left(-w_{1}\right)=-x w_{2}, \\
\bar{U}_{N_{2}} & =y U_{N_{2}}^{1}+(1-y) U_{N_{2}}^{2} .
\end{aligned}
$$

Variable $U_{N_{3}}^{1}$ represents the revenue of $N_{3}$ when choosing the "participating" strategy, while $U_{N_{3}}^{2}$ represents the revenue of $N_{3}$ when choosing the "not participating" strategy, and $\bar{U}_{N_{3}}$ represents the expected revenue. According to Tables 1 and 2, $U_{N_{3}}^{1}, U_{N_{3}}^{2}$, and $\bar{U}_{N_{3}}$ are as follows:

$$
\begin{aligned}
U_{N_{3}}^{1} & =x\left\{\begin{array}{c}
y\left[r_{3}-\left(c_{3}+e_{3}\right)+(\alpha+\beta)\right]+ \\
(1-y)\left[\theta_{3} r_{3}-\left(c_{3}+e_{3}\right)+\alpha\right]
\end{array}\right\}+(1-x)\left\{\begin{array}{c}
y\left[\theta_{3} r_{3}-\left(c_{3}+e_{3}\right)+\beta\right] \\
+(1-y)\left[-\left(c_{3}+e_{3}\right)\right]
\end{array}\right\} \\
& =x\left(\theta_{3} r_{3}+\alpha\right)+y\left(\theta_{3} r_{3}+\beta\right)+x y\left(r_{3}-2 \theta_{3} r_{3}\right)-\left(c_{3}+e_{3}\right), \\
U_{N_{3}}^{2} & =x y\left(r_{3}-c_{3}\right), \\
\bar{U}_{N_{3}} & =z U_{N_{3}}^{1}+(1-z) U_{N_{3}}^{2} .
\end{aligned}
$$

2.3.2. Evolutionary Stability Strategy Solution. The game process between $N_{1}, N_{2}$, and $N_{3}$ is represented by the dynamic replication system composed of the following three differential equations:

$$
\left\{\begin{array}{l}
F(x)=\frac{\mathrm{d} x}{\mathrm{~d} t}=x\left(U_{N_{1}}^{1}-\bar{U}_{N_{1}}\right)=x(1-x)\left[y\left(r_{1}+w_{1}-e_{1}\right)+z\left(\theta_{1} r_{1}-\alpha\right)+y z\left(e_{1}-\theta_{1} r_{1}\right)-c_{1}\right], \\
F(y)=\frac{\mathrm{d} y}{\mathrm{~d} t}=y\left(U_{N_{2}}^{1}-\bar{U}_{N_{2}}\right)=y(1-y)\left[x\left(r_{2}+w_{2}-e_{2}\right)+z\left(\theta_{2} r_{2}-\beta\right)+x z\left(e_{2}-\theta_{2} r_{2}\right)-c_{2}\right], \\
F(z)=\frac{\mathrm{d} z}{\mathrm{~d} t}=z\left(U_{N_{3}}^{1}-\bar{U}_{N_{3}}\right)=z(1-z)\left[x\left(\theta_{3} r_{3}+\alpha\right)+y\left(\theta_{3} r_{3}+\beta\right)+x y\left(c_{3}-2 \theta_{3} r_{3}\right)-\left(c_{3}+e_{3}\right)\right] .
\end{array}\right.
$$

Setting $F(x)=F(y)=F(z)=0$, we obtain eight local equilibrium states of the alliance system, $E_{1}(0,0,0), E_{2}(0,0$, $1), E_{3}(0,1,0), E_{4}(0,1,1), E_{5}(1,0,0), E_{6}(1,0,1), E_{7}(1,1,0)$, and $E_{8}(1,1,1)$. According to the research conclusions of Werner et al. [29], $E_{1}$ to $E_{8}$, and the rest of the points, are nonasymptotically stable. 
TABLE 1: Game payment matrix when the transit country $\left(N_{3}\right)$ chooses "strong participation."

\begin{tabular}{|c|c|c|c|}
\hline \multirow{2}{*}{ Country } & & \multicolumn{2}{|c|}{ Destination country $\left(N_{2}\right)$} \\
\hline & & Participating $(y)$ & Not participating $(1-y)$ \\
\hline Origin country $\left(N_{1}\right)$ & Not participating $(1-x)$ & $\begin{array}{c}r_{1}-c_{1}-\alpha \\
r_{2}-c_{2}-\beta \\
r_{3}-\left(c_{3}+e_{3}\right)+(\alpha+\beta) \\
-w_{1} \\
\theta_{2} r_{2}-c_{2}-\beta \\
\theta_{3} r_{3}-\left(c_{3}+e_{3}\right)+\beta\end{array}$ & $\begin{array}{c}\theta_{1} r_{1}-c_{1}-\alpha \\
-w_{2} \\
\theta_{3} r_{3}-\left(c_{3}+e_{3}\right)+\alpha \\
0 \\
0 \\
-\left(c_{3}+e_{3}\right)\end{array}$ \\
\hline
\end{tabular}

Table 2: Game payment matrix when the transit country $\left(N_{3}\right)$ chooses "weak participation."

\begin{tabular}{|c|c|c|c|}
\hline \multirow{2}{*}{ Country } & & \multicolumn{2}{|c|}{ Destination country $\left(N_{2}\right)$} \\
\hline & & Participating $(y)$ & Not participating $(1-y)$ \\
\hline \multirow{6}{*}{ Origin country $\left(N_{1}\right)$} & \multirow{3}{*}{ Participating $(x)$} & $r_{1}-c_{1}-e_{1}$ & $-c_{1}$ \\
\hline & & $r_{2}-c_{2}-e_{2}$ & $-w_{2}$ \\
\hline & & $r_{3}-c_{3}$ & 0 \\
\hline & \multirow{3}{*}{ Not participating $(1-x)$} & $-w_{1}$ & 0 \\
\hline & & $-c_{2}$ & 0 \\
\hline & & 0 & 0 \\
\hline
\end{tabular}

According to Lyapunov's stability theory [30], the asymptotic stability at the equilibrium point of the differential equation system can be judged by the characteristic roots of the Jacobian matrix of the system. The Jacobian matrix of this system is

$$
\begin{aligned}
& J=\left[\begin{array}{ccc}
\frac{\mathrm{d} F(x)}{\mathrm{d} x} & \frac{\mathrm{d} F(x)}{\mathrm{d} y} & \frac{\mathrm{d} F(x)}{\mathrm{d} z} \\
\frac{\mathrm{d} F(y)}{\mathrm{d} x} & \frac{\mathrm{d} F(y)}{\mathrm{d} y} & \frac{\mathrm{d} F(y)}{\mathrm{d} z} \\
\frac{\mathrm{d} F(z)}{\mathrm{d} x} & \frac{\mathrm{d} F(z)}{\mathrm{d} y} & \frac{\mathrm{d} F(z)}{\mathrm{d} z}
\end{array}\right] \\
& =\left[\begin{array}{ccc}
A & x(1-x)\left[r_{1}+w_{1}-e_{1}+z\left(e_{1}-\theta_{1} r_{1}\right)\right] & x(1-x)\left[\theta_{1} r_{1}-\alpha+y\left(e_{1}-\theta_{1} r_{1}\right)\right] \\
y(1-y)\left[r_{2}+w_{2}-e_{2}+z\left(e_{2}-\theta_{2} r_{2}\right)\right] & B & y(1-y)\left[\theta_{2} r_{2}-\beta+x\left(e_{2}-\theta_{2} r_{2}\right)\right] \\
z(1-z)\left[\theta_{3} r_{3}+\alpha+y\left(c_{3}-2 \theta_{3} r_{3}\right)\right] & z(1-z)\left[\theta_{3} r_{3}+\beta+x\left(c_{3}-2 \theta_{3} r_{3}\right)\right] & C
\end{array}\right],
\end{aligned}
$$

where

$$
\begin{aligned}
A & =(1-2 x)\left[y\left(r_{1}+w_{1}-e_{1}\right)+z\left(\theta_{1} r_{1}-\alpha\right)+y z\left(e_{1}-\theta_{1} r_{1}\right)-c_{1}\right], \\
B & =(1-2 y)\left[x\left(r_{2}+w_{2}-e_{2}\right)+z\left(\theta_{2} r_{2}-\beta\right)+x z\left(e_{2}-\theta_{2} r_{2}\right)-c_{2}\right], \\
C & =(1-2 z)\left[x\left(\theta_{3} r_{3}+\alpha\right)+y\left(\theta_{3} r_{3}+\beta\right)+x y\left(c_{3}-2 \theta_{3} r_{3}\right)-\left(c_{3}+e_{3}\right)\right] .
\end{aligned}
$$

Points $E_{1}(0,0,0), E_{2}(0,0,1), E_{3}(0,1,0), E_{4}(0,1,1), E_{5}$ $(1,0,0), E_{6}(1,0,1), E_{7}(1,1,0)$, and $E_{8}(1,1,1)$ are, respectively, substituted into the Jacobian matrix formulas listed above, and the characteristic roots of the Jacobian 
matrix corresponding to each point can be solved through the determinant operation, of which the results are given in Table 3.

Combined with the actual meaning of model parameters, the three characteristic roots (from Table 3$)$ of $E_{1}(0,0,0)$ are negative, which means it belongs to the asymptotic stability point. As for $E_{2}(0,0,1), E_{3}(0,1,0)$, and $E_{5}(1,0,0)$, at least one characteristic root of the three equilibrium points is positive, so it can be determined that all three of these points are in an unstable state. For $E_{4}(0,1,1), E_{6}(1,0,1)$, $E_{7}(1,1,0)$, and $E_{8}(1,1,1)$, under certain conditions, the four equilibrium points can be asymptotically stable; the stability conditions of equilibrium points are shown in Table 4 .

According to Table 4 , the conditions of $E_{4}(0,1,1)$ and $E_{6}(1,0,1)$ that are asymptotically stable have the same conditional structure but involve different parameters. The conditions of $E_{7}(1,1,0)$ and $E_{8}(1,1,1)$ that are asymptotically stable are mutually exclusive. Therefore, it can be determined that the evolutionary game model has four asymptotically stable scenarios. The following sections focus on scenarios 2,3 , and 4 .

\section{Simulation and Analysis}

3.1. Evolutionary Simulation of the Tripartite Game System. For scenario 2, the condition is defined by $r_{2}+w_{2}<c_{2}+\beta$, $\theta_{1} r_{1}>c_{1}+\alpha$, and $\theta_{3} r_{3}+\alpha>c_{3}+e_{3}$, and we set $r_{1}=40, r_{2}=15, r_{3}=10, \theta_{1}=\theta_{2}=\theta_{3}=0.4, c_{1}=5, c_{2}=10$, $c_{3}=2, e_{1}=e_{2}=3, e_{3}=2, w_{1}=w_{2}=2$, and $\alpha=\beta=8$. The evolution paths (Figure 2 ) show that the system has recently evolved to $E_{1}(0,0,0)$ or $E_{6}(1,0,1)$.

For scenario 3 , the condition is defined by $r_{1}+w_{1}>c_{1}+e_{1}, r_{2}+w_{2}>c_{2}+e_{2}$, and $\alpha+\beta<e_{3}$, and we set $r_{1}=r_{2}=20, r_{3}=10, \theta_{1}=\theta_{2}=\theta_{3}=1 / 3, c_{1}=c_{2}=5, c_{3}=2$, $e_{1}=e_{2}=3 / 2, e_{3}=4, w_{1}=w_{2}=3$, and $\alpha=\beta=3 / 2$. The evolution paths (Figure 3 ) show that the system has finally evolved to $E_{1}(0,0,0)$ or $E_{7}(1,1,0)$.

For scenario 4, the condition is defined by $r_{1}+w_{1}>c_{1}+\alpha, r_{2}+w_{2}>c_{2}+\beta$, and $\alpha+\beta>e_{3}$, and we set $r_{1}=r_{2}=20, r_{3}=10, \theta_{1}=\theta_{2}=\theta_{3}=1 / 3, c_{1}=c_{2}=5, c_{3}=2$, $e_{1}=e_{2}=3 / 2, e_{3}=1, w_{1}=w_{2}=3$, and $\alpha=\beta=3 / 2$. The evolution paths (Figure 4 ) show that the system has recently evolved to $E_{1}(0,0,0)$ or $E_{8}(1,1,1)$.

Figures 2-4 show that all three-party behavior strategies in the dynamic evolutionary game model are convergent when the parameters meet certain conditions, which verifies the rationality of the model. There are two possible evolutionary equilibrium points in each scenario, which indicates that there are unstable factors in the cooperation of the final system.

\subsection{Numerical Simulation of Stability Influencing Factors of} Scenario 4. Scenarios 2 and 3 are essentially bilateral behavioral strategies for the construction of international transport corridors. The cooperative construction of international transport corridors requires a multilateral co-construction mechanism while taking into account the interests of multiple parties. Scenario 4 is a typical multilateral behavior scenario. Comparing parameter conditions with scenarios 2 and 3 , the constraints are less stringent and more accurately reflect reality. Therefore, the following simulation analysis background is set as the relevant parameters to meet the conditions corresponding to scenario 4.

3.2.1. The Impact of Initial Intentions on Evolution. When we set $x=y=z=0.2, x, y, z$ converges to 0 , and the final equilibrium point tends to $(0,0,0)$; when we set $x=y=$ $z=0.5$ or $x=y=z=0.8, x, y, z$ converges to 1 , and the final equilibrium point tends to $(1,1,1)$.

The evolution paths of Figure 5 show that the initial cooperative willingness of the three parties in the evolutionary game system has a direct impact on the evolutionary path and behavior strategy. The greater the initial cooperative willingness of the three parties in the game, the shorter the time required for the game system to finally move towards "cooperation." When the system evolves towards "cooperation," the origin country and the destination country are more active than the transit country, while the system shows the opposite trend when the system moves towards "noncooperation." This shows that, for the cooperation and construction of an international transport corridor, although it has good benefits, if the initial willingness of the parties to cooperate is low, the cooperation would tend to fail.

3.2.2. The Impact of Benefits on Evolution. We set the initial cooperation intention to $x=y=z=0.3$. The evolution paths are shown in Figure 6. Under this setting, as the benefits of participating in international transport corridor construction increase, the speed of the system converging to the equilibrium point $(1,1,1)$ accelerates, and the origin and destination countries converge to the state of cooperation faster than that of the transit country. Simulation analysis shows that the greater the expected benefits of all parties involved in corridor construction, the better the stability of cooperation.

3.2.3. The Impact of Costs on Evolution. The costs increase setting slows down the system's convergence to cooperation (Figure 7). When cost increases up to a certain level, it ultimately changes the final path of system evolution. When we set $c_{1}=c_{2}=10$, the system evolution path finally converges to $(0,0,0)$, showing that when the cost increases to a certain level, it reduces the enthusiasm of the origin and destination countries to participate in corridor development and can lead to noncooperation.

Costs are an important factor affecting the cooperation in the construction of international transport corridors, and the investment in cross-border transportation infrastructure is usually large, which often becomes a practical reason for restricting the enthusiasm of countries along the route to participate in the construction. 
TABLE 3: The eigenvalues of the equilibrium points.

\begin{tabular}{lccc}
\hline The equilibrium point & Eigenvalues $\lambda_{1}$ & Eigenvalues $\lambda_{2}$ & Eigenvalues $\lambda_{3}$ \\
\hline$E_{1}(0,0,0)$ & $-c_{1}$ & $-c_{2}$ & $-\left(c_{3}+e_{3}\right)$ \\
$E_{2}(0,0,1)$ & $\theta_{1} r_{1}-c_{1}-\alpha$ & $\theta_{2} r_{2}-c_{2}-\beta$ & $c_{3}+e_{3}$ \\
$E_{3}(0,1,0)$ & $r_{1}+w_{1}-c_{1}-e_{1}$ & $\theta_{3} r_{3}+\beta-c_{3}-e_{3}$ \\
$E_{4}(0,1,1)$ & $r_{1}+w_{1}-c_{1}-\alpha$ & $-\left(\theta_{2} r_{2}-c_{2}-\beta\right)$ & $-\left[\left(\theta_{3} r_{3}+\beta\right)-\left(c_{3}+e_{3}\right)\right]$ \\
$E_{5}(1,0,0)$ & $c_{1}$ & $r_{2}+w_{2}-c_{2}-e_{2}$ & $\theta_{3} r_{3}+\alpha-c_{3}-e_{3}$ \\
$E_{6}(1,0,1)$ & $-\left(\theta_{1} r_{1}-c_{1}-\alpha\right)$ & $r_{2}+w_{2}-c_{2}-\beta$ & $-\left[\left(\theta_{3} r_{3}+\alpha\right)-\left(c_{3}+e_{3}\right)\right]$ \\
$E_{7}(1,1,0)$ & $-\left(r_{1}+w_{1}-c_{1}-e_{1}\right)$ & $-\left(r_{2}+w_{2}-c_{2}-e_{2}\right)$ & $\alpha+\beta-e_{3}$ \\
$E_{8}(1,1,1)$ & $-\left(r_{1}+w_{1}-c_{1}-\alpha\right)$ & $-\left(r_{2}+w_{2}-c_{2}-\beta\right)$ & $-\left(\alpha+\beta-e_{3}\right)$ \\
\hline
\end{tabular}

TABle 4: Asymptotically stable point and its existence conditions.

\begin{tabular}{lcc}
\hline Asymptotically stable point & Conditions & Scenarios \\
\hline$E_{1}(0,0,0)$ & Forever admitted & - \\
$E_{4}(0,1,1)$ & $r_{1}+w_{1}<c_{1}+\alpha, \theta_{2} r_{2}>c_{2}+\beta, \theta_{3} r_{3}+\beta>c_{3}+e_{3}$ & 1 \\
$E_{6}(1,0,1)$ & $r_{2}+w_{2}<c_{2}+\beta, \theta_{1} r_{1}>c_{1}+\alpha, \theta_{3} r_{3}+\alpha>c_{3}+e_{3}$ & 2 \\
$E_{7}(1,1,0)$ & $r_{1}+w_{1}>c_{1}+e_{1}, r_{2}+w_{2}>c_{2}+e_{2}, \alpha+\beta<e_{3}$ & \\
$E_{8}(1,1,1)$ & $r_{1}+w_{1}>c_{1}+\alpha, r_{2}+w_{2}>c_{2}+\beta, \alpha+\beta>e_{3}$ & \\
\hline
\end{tabular}

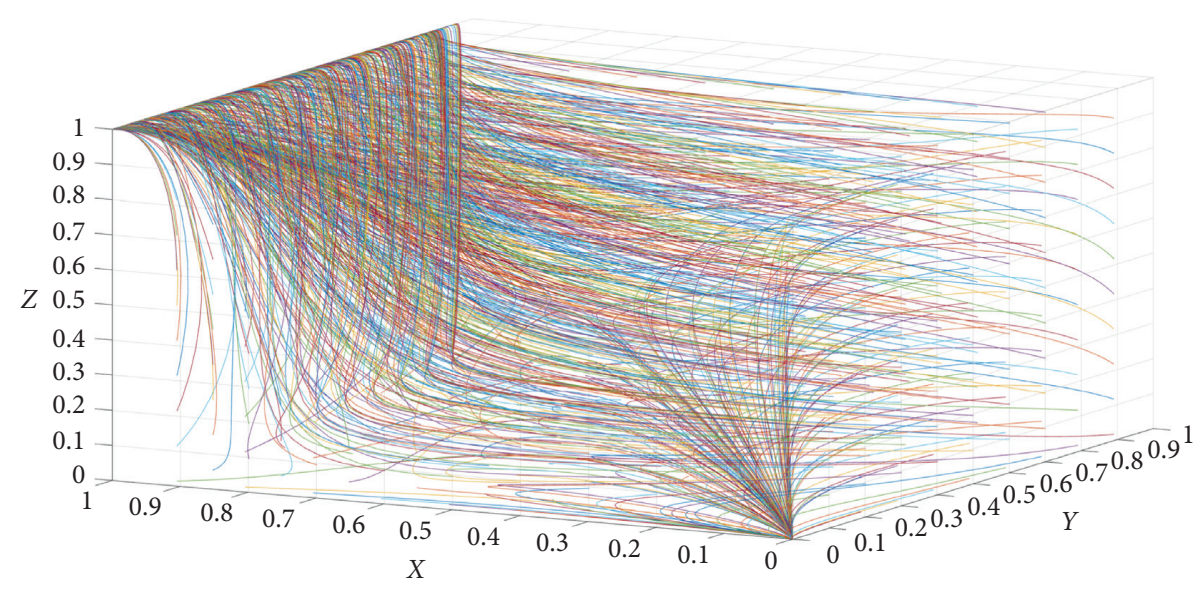

FIGURE 2: Evolution paths of scenario 2.

3.2.4. The Impact of Transfer Payments on Evolution. As the incentive transfer payment (subsidy) increases, the transit country's behavioral strategy converges to "cooperation" faster (Figure 8). At the same time, it can be seen that, with the increase in subsidies, the rate of evolution of the origin and destination countries towards "cooperation" has slowed down. In the construction of international transport corridors, transit countries tend to obtain subsidies from other countries, and subsidies have become a sensitive variable that stimulates and facilitates cooperation.

In fact, excessive subsidies increase the overall cost of participating in the construction of the corridor between the origin and destination countries, which in turn will reduce the enthusiasm for participation. The implication is that reasonable and appropriate subsidies should be a consensus among countries along the route; otherwise, they would not be able to better promote cooperation.

3.2.5. The Impact of Sunk Costs and Reputation on Evolution. As $w$ increases (the potential sunk costs and reputation losses increase; Figure 9), the speed of the system converging to cooperation increases; that is, the probability that the behavioral strategies of the origin and destination countries will tend to be in a "cooperative" state increases. Simultaneously, this change has little impact on transit countries. 


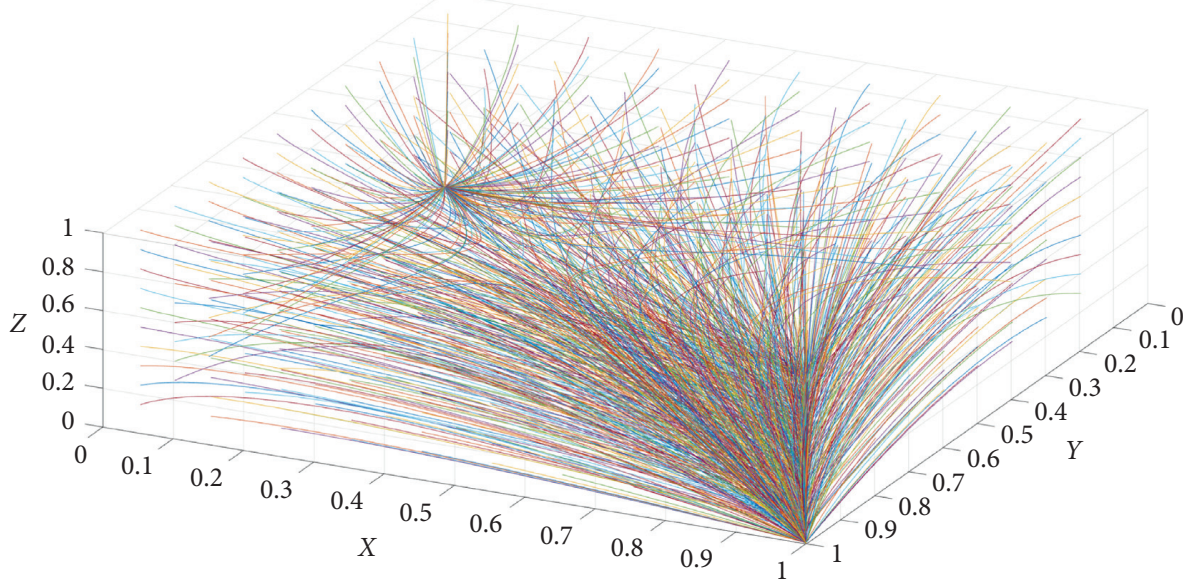

Figure 3: Evolution paths of scenario 3.

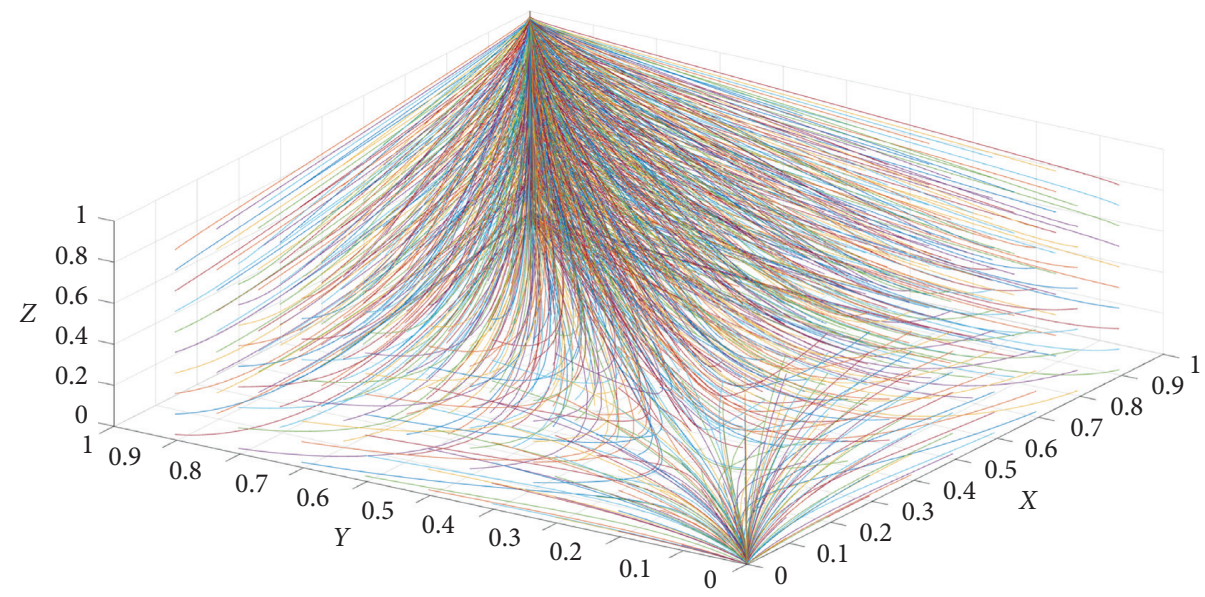

FIgURE 4: Evolution paths of scenario 4.

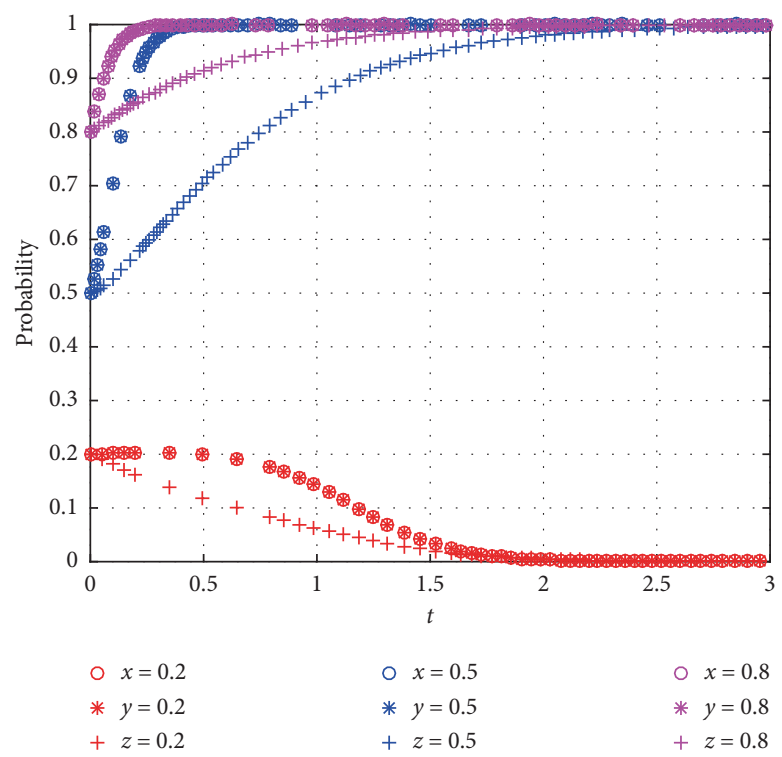

Figure 5: Evolution paths of scenario 4 under different initial intentions. 


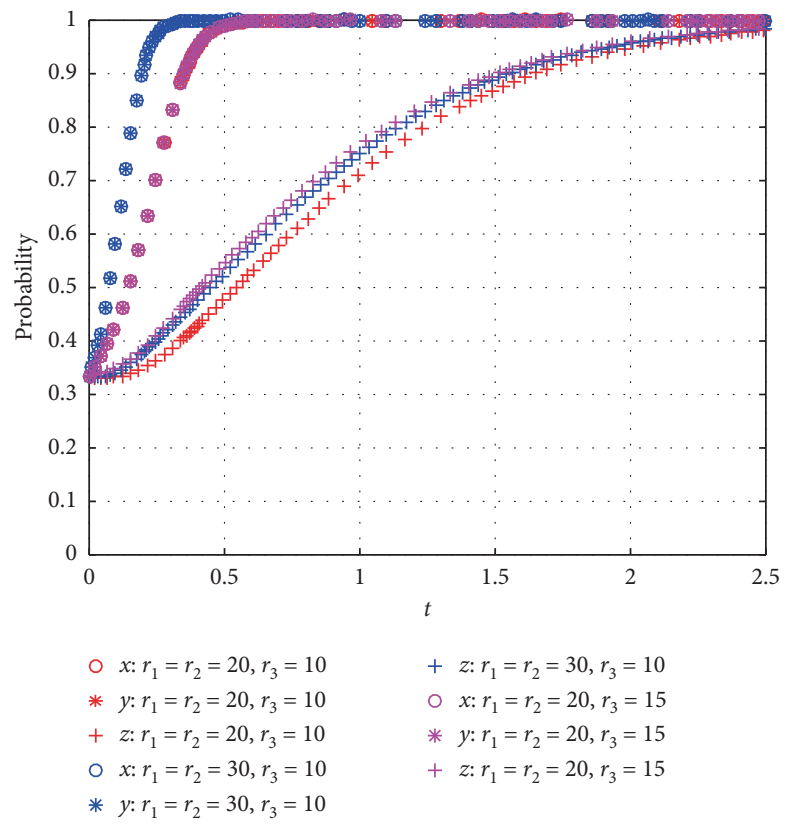

FIGURE 6: Evolution paths of scenario 4 under different benefits.

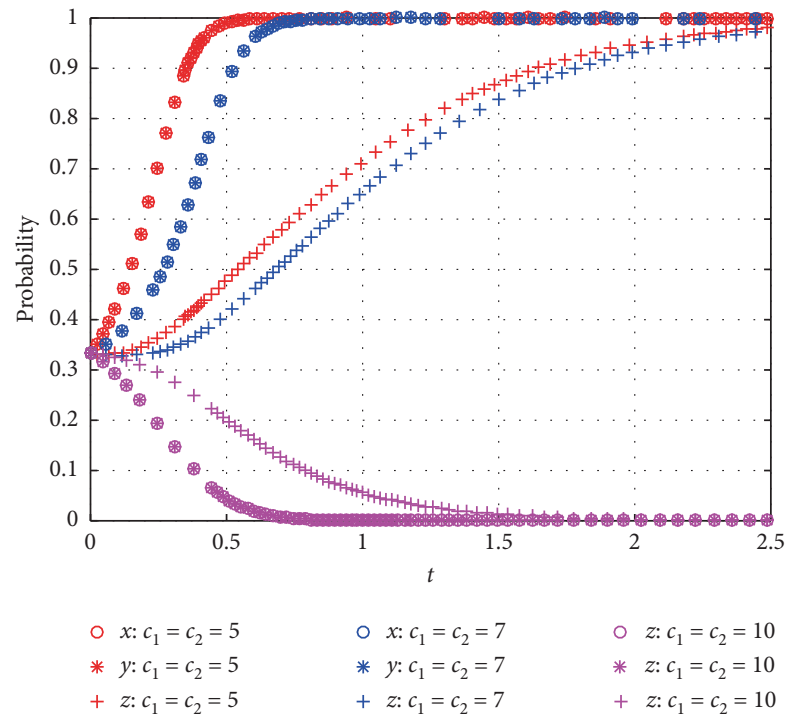

Figure 7: Evolution paths of scenario 4 under different costs.

3.2.6. The Impact of Residual Benefits on Evolution. When the trilateral cooperation degenerates into bilateral cooperation, the residual benefit coefficient $\left(\theta_{i}\right)$ of bilateral cooperation increases, the speed of system convergence to cooperation accelerates (Figure 10). This indirectly indicates that the increase in the proportion of benefits brought about by "bilateral cooperation" is

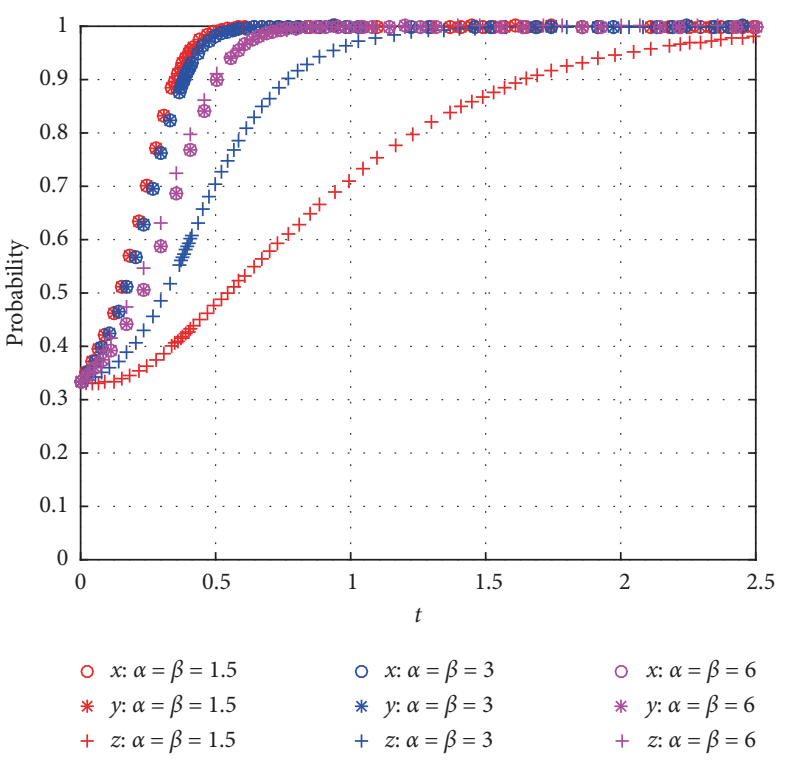

FIgURE 8: Evolution paths of scenario 4 under different transfer payments.

conducive to achieving tripartite cooperation. If the starting country or the destination country abandons cooperation, the smaller the proportion of the remaining partner's income decreases, the greater the probability of the system evolving to cooperation. 


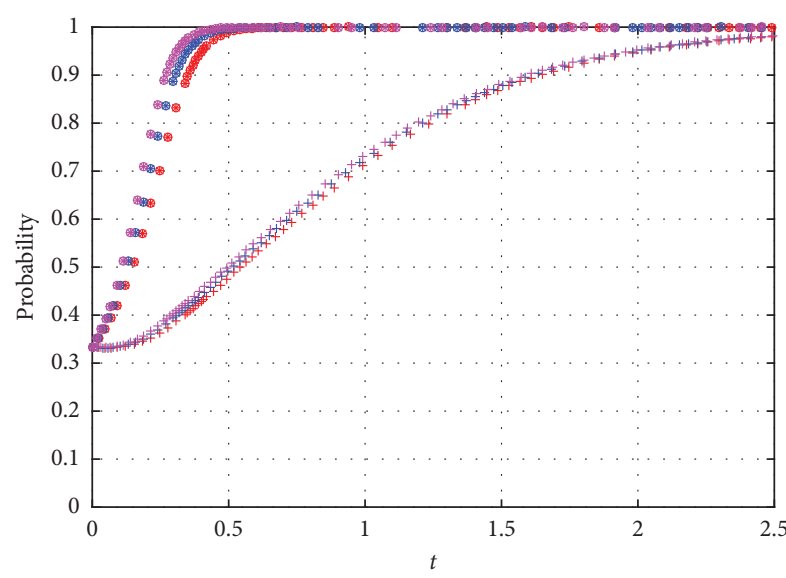

$$
\begin{array}{lll}
\circ x: w_{1}=w_{2}=3 & \circ x: w_{1}=w_{2}=5 & \circ x: w_{1}=w_{2}=7 \\
* y: w_{1}=w_{2}=3 & * y: w_{1}=w_{2}=5 & * y: w_{1}=w_{2}=7 \\
+z: w_{1}=w_{2}=3 & +z: w_{1}=w_{2}=5 & +z: w_{1}=w_{2}=7
\end{array}
$$

FIgURE 9: Evolution paths of scenario 4 under different sunk costs and reputation.

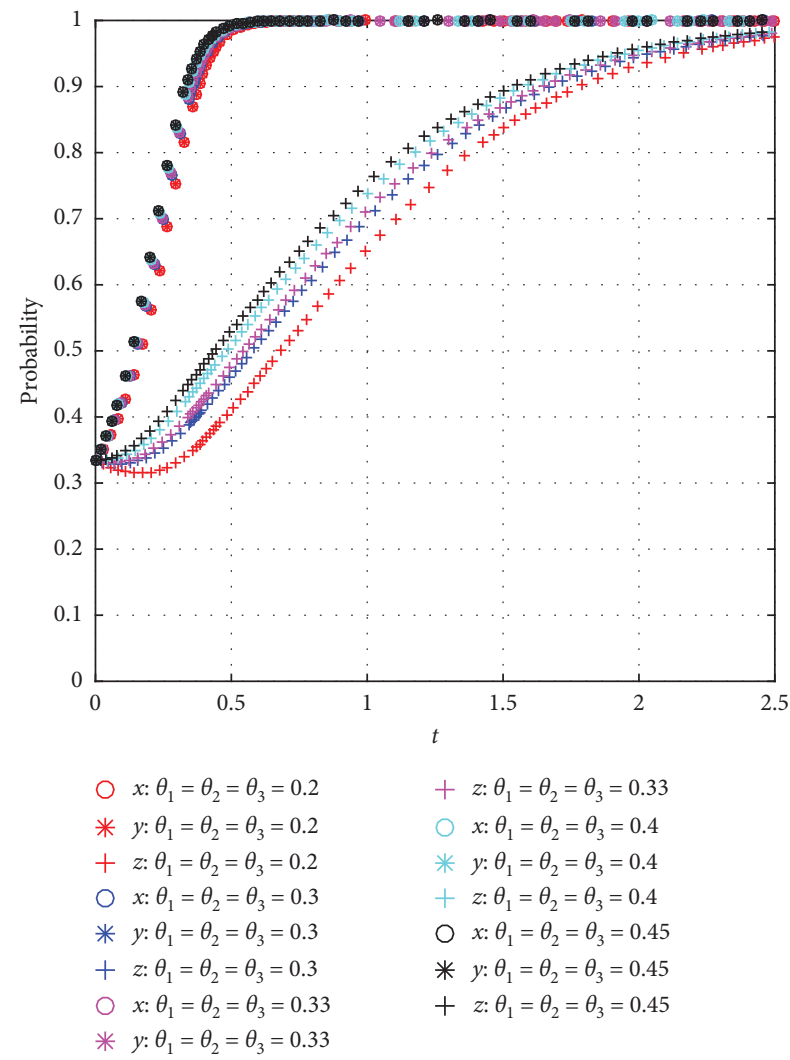

FIgURE 10: Evolution paths of scenario 4 under different residual benefit coefficients.

\section{Conclusions}

First, for the cooperative construction of international transport corridors, a low initial willingness to cooperate leads to noncooperation, which in turn slows down or even stalls the efficiency of international transport corridors. To promote the construction of international transport corridors, all parties need to have a strong willingness to cooperate; otherwise, the cooperation agreement has a greater probability of becoming invalid. This also shows that the development of international transport corridors is long term and complex.

Second, the higher the cost of the construction of international transport corridors, the greater the probability that the tripartite behavior strategy combination will evolve to "noncooperation." The greater the potential benefits brought by the construction of international transport corridors, the greater the probability of cooperation. Multilateral cooperation degenerates into bilateral cooperation. This shows that the higher the investment cost of the corridor, the slower the efficiency improvement from it. Thus, international transport corridors with good developmental prospects and benefits will accelerate efficiency improvements when participating countries actively put in effort.

Third, there is an optimal scale of transfer payments. As the scale of transfer payments increases, the probability that the system will evolve to cooperation also increases. Transfer payments that exceed the optimal scale will have an adverse impact on cooperation. This shows that appropriate transfer payments can increase the enthusiasm of transit countries to participate in channel construction, but when the transfer burden is too heavy, it reduces the enthusiasm of the origin and destination countries to cooperate.

Finally, in the multilateral cooperation that enhances the effectiveness of international transport corridors, sunk cost and reputational loss mechanisms have a positive effect on restricting the origin and destination country from unilaterally abandoning participation or suspending investment.

\section{Data Availability}

All the data and materials are included within the manuscript.

\section{Conflicts of Interest}

The author declares no conflicts of interest.

\section{Acknowledgments}

This research was supported by the Chongqing Social Science Planning Project (no. 2017QNGL58), the Humanities and Social Science Research Planning Project of Chongqing Education Commission (no. 19SKGH067), and the Special Research Fund for Major Theoretical Research and Interpretation of Philosophy and Social Sciences of Chongqing Education Commission.

\section{References}

[1] L. Albrechts and T. Tasan-Kok, "Corridor and axis development," in International Encyclopedia of Human Geography, A. Kobayashi, Ed., Elsevier, Oxford, UK, 2nd edition, 2020.

[2] M. Furmankiewicz, K. Buryło, and S. Dołzbłasz, "From service areas to empty transport corridors? the impact of border openings on service and retail facilities at polish-Czech border 
crossings," Moravian Geographical Reports, vol. 28, no. 2, pp. 136-151, 2020.

[3] Se-il Mun, "Joint provision of transportation infrastructure," Economics of Transportation, vol. 19, pp. 1-9, 2019.

[4] J. Park, C. Kwon, and M. Son, "Economic implications of the Canada-U.S. border bridges: applying a binational local economic model for international freight movements," Research in Transportation Business \& Management, vol. 11, pp. 123-133, 2014.

[5] S. Hanaoka, M. Sota, T. Kawasaki, and R. G. Thompson, "Performance of cross-border corridors in east Africa considering multiple stakeholders," Transport Policy, vol. 81, pp. 117-126, 2019.

[6] A. Quium, "Transport corridors for wider socio-economic development," Sustainability, vol. 11, no. 19, pp. 1-23, 2019.

[7] N. Otsuka, F. C. Günther, I. Tosoni, and C. Braun, "Developing trans-European Railway corridors: lessons from the rhine-alpine corridor," Case Studies on Transport Policy, vol. 5, no. 4, pp. 527-536, 2017.

[8] A. D. Perl and A. R. Goetz, "Corridors, hybrids and networks: three global development strategies for high speed rail," Journal of Transport Geography, vol. 42, pp. 134-144, 2015.

[9] M. Jain and J. Mathias, "Analysing transport corridor policies: an integrative approach to spatial and social disparities in India," Journal of Transport Geography, vol. 86, pp. 1-10, 2020.

[10] G. Lesutis, "How to understand a development corridor? the case of Lamu Port-South Sudan-Ethiopia-Transport corridor in Kenya," Area, vol. 52, no. 3, pp. 600-608, 2019.

[11] C. Kunaka and R. Carruthers, Trade and Transport Corridor Management Toolkit, World Bank, Washington, DC, USA, 2014.

[12] Y. Adzigbey, C. Kunaka, and T. N. Mitiku, Institutional Arrangements for Transport Corridor Management in SubSaharan Africa, World Bank, Washington, DC, USA, 2007.

[13] M. Öberg, K. L. Nilsson, and C. M. Johansson, "Complementary governance for sustainable development in transport: the European TEN-T core network corridors," Case Studies on Transport Policy, vol. 6, no. 4, pp. 674-682, 2018.

[14] H. Priemus and W. Zonneveld, "What are corridors and what are the issues? Introduction to special issue: the governance of corridors," Journal of Transport Geography, vol. 11, no. 3, pp. 167-177, 2003.

[15] M. Krongkaew, "The development of the greater Mekong subregion (GMS): real promise or false hope?" Journal of Asian Economics, vol. 15, no. 5, pp. 977-998, 2004.

[16] K. Yildirir, "Importance of transport corridors in regional development: the case of TRACECA," Sosyoekonomi, vol. 24, no. 23, pp. 163-182, 2015.

[17] A. F. Isik and Z. Zou, "China-Turkey security cooperation under the background of the 'Belt and Road' and the 'Middle corridor' initiatives," Asian Journal of Middle Eastern and Islamic Studies, vol. 13, no. 2, pp. 278-293, 2019.

[18] I. Anastasiadou, "Iron silk roads: the geopolitics of past and present initiatives for the revival of eurasian trade through overland transport corridors," Cambridge Journal of Regions, Economy and Society, vol. 12, no. 1, pp. 57-75, 2019.

[19] L. Zhao, Y. Zhao, and Q. Hu, "Evaluation of consolidation center cargo capacity and loctions for China Railway express," Transportation Research Part E, vol. 117, pp. 58-81, 2018.

[20] S. P. Singh and M. Sharma, INSTC: India-Russia's Trade to Get a Major Boost, RIAC, Moscow, Russia, 2017.

[21] S. S. Kulkarni and H. S. K. Nathan, "The elephant and the tiger: energy security, geopolitics, and national strategy in
China and India's cross border gas pipelines," Energy Research \& Social Science, vol. 11, pp. 183-194, 2016.

[22] D. Helbing, D. Brockmann, T. Chadefaux et al., "Saving human lives: what complexity science and information systems can contribute," Journal of Statistical Physics, vol. 158, no. 3, pp. 735-781, 2015.

[23] J. W. Weibull and M. Press, Evolutionary Game Theory, MIT Press, Cambridge, MA, USA, 1995.

[24] O. Galor and S. Michalopoulos, "Evolution and the growth process: natural selection of entrepreneurial traits," Journal of Economic Theory, vol. 147, no. 2, pp. 759-780, 2012.

[25] W. Tianhua, D. Liu, and L. Wang, "Stochastic evolutionary game model of international anti-terrorism alliance under uncertain environment," Systems Engineering-Theory \& Practice, vol. 39, no. 12, pp. 3139-3150, 2019.

[26] H. Dechun, L. Chen, and C. Wu, "An analysis of the conflict of international water allocation based on the evolutionary game," China Rural Water and Hydropower, vol. 4, pp. 90-96, 2015.

[27] L. I. Feng and Y. Yang, "A study on the economic and trade cooperation in the construction of Bangladesh-China-IndiaMyanmar economic corridor: based on dynamic evolution game model," Economic Problems, vol. 7, pp. 77-84, 2018.

[28] M. A. Guanghong, C. Bao, and E. Shan, "Analysis of stability of "the Belt and Road" PPP infrastructure projects cooperation based on evolutionary game," Journal of Shanghai University (Natural Science Edition), vol. 25, no. 4, pp. 612624, 2019.

[29] W. Güth, G. Kirchsteiger, and K. Ritzberger, "Imperfectly observable commitments inn-player games," Games and Economic Behavior, vol. 23, no. 1, pp. 54-74, 1998.

[30] H. K. Khalil, "Lyapunov'S stability theory," in Encyclopedia of Systems and Control, J. Baillieul and T. Samad, Eds., Springer, London, UK, 2013. 